\title{
Unique Premedical Education Experience in Public Health and Equity: Combined BA/MD Summer Practicum
}

\author{
Amy Clithero ${ }^{1}$, Robert Sapien ${ }^{2}$, Judith Kitzes ${ }^{3}$, Summers Kalishman ${ }^{1}$, Sharon Wayne ${ }^{4}$, \\ Brian Solan ${ }^{1}$, Lana Wagner ${ }^{1}$, Valerie Romero-Leggott ${ }^{1}$ \\ ${ }^{1}$ Family and Community Medicine, University of New Mexico School of Medicine, Albuquerque, USA \\ ${ }^{2}$ Emergency Medicine, University of New Mexico School of Medicine, Albuquerque, USA \\ ${ }^{3}$ Internal Medicine, University of New Mexico School of Medicine, Albuquerque, USA \\ ${ }^{4}$ Office of Program Evaluation, Education and Research, University of New Mexico School of Medicine, \\ Albuquerque, USA \\ Email: AClithero@salud.unm.edu
}

Received September $27^{\text {th }}, 2012$; revised November $1^{\text {st }}, 2012$; accepted November $18^{\text {th }}, 2012$

Copyright (C) 2013 Amy Clithero et al. This is an open access article distributed under the Creative Commons Attribution License, which permits unrestricted use, distribution, and reproduction in any medium, provided the original work is properly cited.

\begin{abstract}
Background: Physicians will need increased skills in the areas of public health, equity based interventions and patient safety skills to address the medical needs of patients in the $21^{\text {st }}$ century. Premedical education and experiences is one strategy to address these areas. Methods: A one month rural summer practicum was developed for all BA/MD students. Key components include: 1) physician shadowing; 2) tutorials; 3) narrative writings; and 4) group community projects. Students attend a preparatory community service course prior to the practicum. Pre/post practicum surveys assessed students' attitudes and skills with respect to community interventions. Post practicum surveys evaluate the elements of the practicum. Results: Survey results demonstrated no significant change in opinions or skills and activities with respect to community interventions. Highly rated items in the post practicum evaluations included physician shadowing, community activities, and opportunities to learn from others. Conclusions: A pre-medical practicum experience can help students define their roles as future physicians and increase their interactions within communities around public health issues. Whether this translates into improved involvement of physicians using public health equity based interventions is an area of ongoing study.
\end{abstract}

Keywords: Public Health; Pre-Medical Education; Health Equity; Service Learning; Combined BA/MD Program

\section{Introduction}

The changing needs and expectations of society in preparing physicians for the $21^{\text {st }}$ century have resulted in several published medical education reform papers. The central theme cited in the majority of the reports is based on the Institute of Medicine's 2003 report, "Who Will Keep the Public Healthy? Educating Public Health Professionals for the $21^{\text {st }}$ Century". (IOM) Contemporary society is encouraging more focus on public health, equity-based care delivery, and partnerships between Academic Health Centers (AHC) and the communities they serve. These reports make recommendations including: 1) the need to retool required premedical college science curriculum, 2) incorporate known educational learning research for structured, self-directed educational activities, and 3) to include more individual competency based assessment tools to guarantee that physicians are competent, ethical and professional (Irby 2010; Miller, 2010; Alpern, 2009; Leape, 2010; Fletcher, 2008). Additionally, "all undergraduates should have access to education in public health (IOM 2003). As noted by Cashman and Seifer (2008) "Service-learning, a type of experiential learning, is an effective and appropriate vehicle for teaching public health and developing public health literacy".
The commitment to these recommendations by the University of New Mexico Health Sciences Center School of Medicine (UNM HSC SOM) is evidenced in the HSC vision "working with community partners, the UNM HSC will make more progress in health and health equity than any other state by 2020" (Strategic Plan, 2010). The context of this vision is set within the contraints of the following challenges. New Mexico is geographically the fifth largest state in the United States, ranks $36^{\text {th }}$ in population size with two million residents, and is one of four minority-majority states. It is a rural state with only nine cities having populations over 30,000 and ranks 43rd in per capita income (NM Quick Links, 2010; US Census Bureau, 2010). With regards to healthcare access, half of New Mexico's population lives in rural areas, yet two-thirds of its physicians practice in urban areas. Thirty-two of its 33 counties are designated as Health Professional Shortage Areas as determined by the Health Resources and Services Administration (HRSA, 2010) and NM ranks 16th highest in frontier counties.

In 2006, to support its mission and reflect the call to reform medical education, UNM SOM implemented the Combined BA/MD Degree program. This eight-year program results in both a Bachelor of Arts and a Medical Degree. Its primary goal is to improve the health and well-being of New Mexicans. It is 
designed to help address the physician shortage in New Mexico by selecting a diverse group of high school seniors who are committed to practice in New Mexico's communities of greatest need (Cosgrove, 2007; Rabinowitz, 1999). The BA curriculum is designed to prepare the students for entrance into the UNM SOM program by emphasizing public health and equity based perspectives.

Overview elements of the Bachelor of Arts/Medical Degree (BA/MD) program at the University of New Mexico include: (Combined BA/MD, 2010).

- Partnership between the Colleges of Arts \& Sciences and the School of Medicine.

- Undergraduate portion fully funded by the New Mexico State Legislature including tuition, housing.

- BA/MD students pursue one of three degree options for their undergraduate degree, all of which emphasize science and liberal arts coursework.

- Option 1: Arts and Sciences concentration;

- Option 2: Health Medicine and Human Values concentration;

- Option 3: Biomedical Science concentration.

The curriculum is designed to provide a strong foundation for practicing medicine with sensitivity to New Mexicans and their public health and medical needs. Included in the customized curriculum are five integrated health seminars and participation in a summer community health project (Summer Practicum) in a New Mexico rural or medically-underserved community

Table 1 describes the five BA/MD Health Medicine and Values Seminars and Summer Practicum which make up the unique backbone of the BA curriculum. These classes prepare the students to enter the MD curriculum with an enhanced exposure to public health, ethics, health economics, cultural diversity awareness, literature, fine arts and medicine, and New Mexico population health variables. These topics continue in the MD curriculum culminating in all students receiving a professional development Certificate in Public Health along with their MD degree.

The Summer Practicum is an innovation in undergraduate premedical preparation. The educational learning models that support its development were Vygotsky's historical sociocultural approach, service learning, small group problem based tutorials, self-reflective metacognitive narrative writing and professional identity development through shadowing (JohnSteiner, 1996; Choon-Eng, 2009; Levine, 2008; Shapiro, 2006;

Table 1.

Health Medicine Human Values (HVMV) Seminars.

Contours of Health in New Mexico: Ethnic, economic, demographic, and geographic variables impacting public health in New Mexico and the Southwest.

Literature, Fine Arts, \& Medicine; Links among health, illness, literature and the arts, encompassing a diverse range of forms and genres.

Health Economics, Politics, and Policy: Political and economic forces that impact health care policies and practices.

Health and Cultural Diversity: Cultural variables that affect the experience and practice of health and health care.

Ethics, Medicine, and Health: Ethical and legal considerations that influence medical practices and decision-making.

Summer Practicum: Introduction to the Core Functions and 10 Essential Services of Public Health.
Kitsis, 2011; Sheu, 2011).

While there are numerous medical school and other health professional examples of community service learning and community project requirements as part of the medical curriculum, a PubMed search yielded no information on guided undergraduate premedical community service opportunities. Because most international medical schools take students directly from high school, aspects of this model may be of interest to medical training outside the USA such as pre-practicum seminars, on-site faculty guidance and reflection via narrative writing.

Through community engagement, the ultimate goal of the Summer Practicum is for students to experience the connection between social determinants of health and the health of community members, and how public health and medicine are intertwined. Whether they recognize this as part of public health or not, physicians diagnose, monitor health, mobilize community partnerships, provide and evaluate care, and conduct research and, by doing so, solidify the public health and medicine relationship.

\section{Curriculum}

The Summer Practicum is a one month service-learning experience designed to enhance students' knowledge and understanding of health issues and healthcare practice in rural and underserved communities.

Given that there are numerous definitions of service-learning, we adapted our definition from a variety of sources found on the Community-Campus Partnerships for Health (CCPH) website. $\mathrm{CCPH}$ is a nonprofit organization that "promotes health equity and social justice through partnerships between communities and academic institutions.

http://depts.washington.edu/ ccph/index.html

The definition we adopted is:

Service learning has been defined as a type of experiential education that involves people in both community service and education. Service learning provides developmental opportunities that promote personal, social, and intellectual growth, as well as civic responsibility and career exploration." Specific components that are emphasized in our program include:

1) Active integrated learning drawing lessons from the experience of performing service work and enhancing the knowledge, values and skills of the participants

2) Engaging students and communities in as many aspects of the project planning as possible

3) Meeting a real need in the community with age appropriate, well organized outcomes oriented service

4) Collaboration involves all stakeholders in the planning, execution and evaluation of the service

5) Reciprocity provides benefit to the recipient (BA/MD communities) and the provider of the service (BA/MD students)

6) Reflection allows time for contemplation before (to prepare), during (to troubleshoot) and after (to process and assess)

Students participate in the practicum during the second summer of the BA portion of the BA/MD program. Figure 1 gives an overview of the preparatory sessions and Summer Practicum. Prior to the practicum, students attend an 8-week pre-practicum course that provides foundational information on public health concepts, community assessment tools and community service basics. Students complete on-line Health Insurance Portability and Accountability Act (HIPAA) training, 


\begin{tabular}{|c|c|c|c|c|c|c|c|}
\hline \multicolumn{8}{|c|}{ Preparatory Spring Curriculum } \\
\hline Week 1 & Week 2 & Week 3 & Week 4 & Week 5 & Week 6 & Week 7 & Week 8 \\
\hline $\begin{array}{c}\text { Lecture \& } \\
\text { Discussion: } \\
\text { History of Public } \\
\text { Health and } \\
\text { Medicine }\end{array}$ & $\begin{array}{l}\text { Community } \\
\text { Coordinator } \\
\text { Introductions }\end{array}$ & $\begin{array}{l}\text { Introduction } \\
\text { to Social } \\
\text { Determinants } \\
\text { of Health }\end{array}$ & $\begin{array}{l}\text { Introduction to } \\
\text { Health Sciences } \\
\text { Library services } \\
\text { and Researching } \\
\text { Literature }\end{array}$ & $\begin{array}{c}\text { Community } \\
\text { Asset Mapping }\end{array}$ & $\begin{array}{c}\text { Panel } \\
\text { Presentation } \\
\text { by UNM Faculty } \\
\text { on Public Health } \\
\text { \& Medicine in } \\
\text { Action }\end{array}$ & $\begin{array}{c}\text { Basic Clinical } \\
\text { Skills \& } \\
\text { Professionalism } \\
\text { Training }\end{array}$ & $\begin{array}{l}\text { Practicum } \\
\text { Practicalities: } \\
\text {-HIPAA Training } \\
\text {-CITI Training } \\
\text {-Bloodborne } \\
\text { Pathogen } \\
\text { Training }\end{array}$ \\
\hline & & & & & & & \\
\hline
\end{tabular}

BA/MD Summer Practicum Curriculum

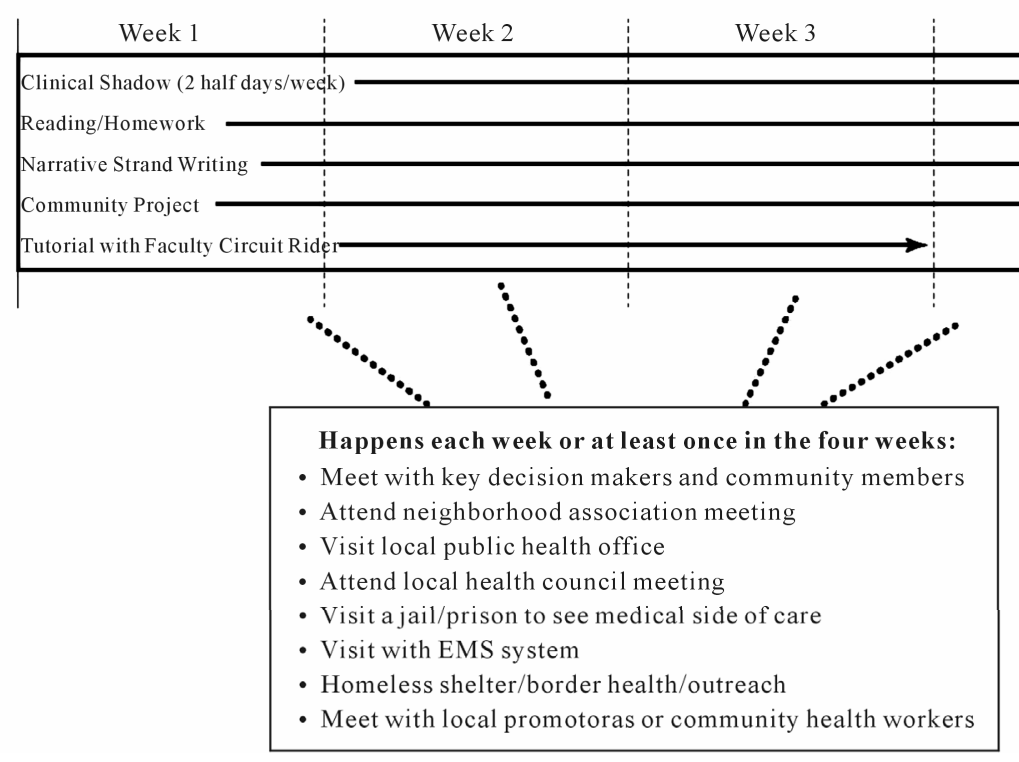

Figure 1.

Legend: Pre-practicum preparatory sessions and summer practicum curriculum overview.

Infection Control and Institutional Research Board (IRB) training. Both the students and physicians sign a student code of conduct (see attachment). In addition, students receive training in professionalism including how to introduce themselves to patients and ask permission to remain in the room during an exam or procedure. At the completion of the preparatory course, students are divided into groups and sent to live for one month in a rural New Mexico community, the Practicum.

The practicum has four components: 1) shadowing a local community physician; 2) tutorials and homework assignments; 3) narrative writing; and 4) community project. By the end of the practicum experience, it is expected that students will be able to define a community; identify a community concern; discuss this issue of concern from both a clinical and a public health perspective; identify possible solutions to the issue and; suggest ways of monitoring the impact of solutions. Students have assistance from community liaisons, local physicians, UNM SOM faculty circuit riders, and UNM SOM faculty mentors.

Tutorials demonstrate the intertwining areas of public health and medicine. Week 1 examines environmental factors (neighborhood impact on health). Students investigate their community by answering 25 questions by conducting a windshield survey of both a "wealthy" neighborhood and an economically disadvantaged neighborhood as identified by their community coordinator. The goal is for the students to learn about the physical composition of the community as well as the people who live there and the services and facilities that are available. The students are also asked to take photos that represent their community as a whole. For example, if they had to describe their community to someone who didn't speak a common language, what photos would capture the spirit of their community? Week 2 focuses on structural factors (impact of wealth on health). Students are asked to first think about their personal beliefs regarding poverty, health and roles/responsibilities of physicians. They then read three articles, "Poverty in America: How Public Health Practice Can Make a Difference" (Erwin, 2008), "Poverty and Ill Health: Physicians Can, and Should, Make a Difference" (McCally, 1998) and "The Nexus of Poverty, Hunger and Homelessness in New Mexico" (Page-Reeves, 2013). The students then choose one of the community clinics or hospital where they are shadowing and examine payment and fees for a particular condition. Finally, they are asked to find a list of items new parents should have (a layette) for a newborn baby. They are given a list of products and they have to "best guess" as to what the item costs. The students then go out as a group to a local store and record the actual prices. Week 3 emphasizes inequities and power gradients (impact of education on health). After reading "Giving everyone the health of the educated: an examination of whether social change would save more lives than medical advances" (Woolfe, 2007) and "the Robert Wood Johnson Foundation: Commission to Build a Healthier America: Education matters for health" 
(2009), students are asked to list and discuss some of the reasons minority groups might have increased mortality rates; how education might improve the health of individuals and the impact of education on a particular condition. Week 4 is a culmination of the first three weeks by talking about policy and advocacy. Students are assigned readings including "Emergency Medicine and Public Health: Stopping Emergencies before the 911 Call" (Kellerman, 2009) and "Imposing Personal Responsibility for Health" (Steinbrook, 2006). Students look at existing prevention initiatives, legal remedies, public health initiatives and medical awareness campaigns while reflecting on personal responsibility for health conditions.

Shadowing a local physician is an element of the Summer Practicum curriculum, through which the student experiences the rewards and challenges of being a rural healthcare practitioner, and the advantages/disadvantages of the preceptor's specialty, practice model and location. They watch practitioners interact with their patients and see a variety of medical problems and learn to link the patients' medical problems with public health concepts. This hands-on experience is supplemented with weekly visits by a UNM faculty circuit rider who relates readings and homework assignments to what students are experiencing in the community. Community coordinators who live and work in the assigned community also help guide the student experience and give local perspectives.

The narrative writing element "promotes self-reflection and increases self-awareness" (Shapiro, 2006). These megacognitive skills may carry over into the medical school professionalism curriculum. Most people reflect, but the skill medical professionals need, critical reflection, is different: According to UCSF LeaP Learning from your Experiences as a Professional: Guidelines for Critical Reflection (Aronson, 2012), Critical Reflection is "the process of analyzing, questioning and reframing a personal experience to enhance learning and inform future behavior." It is a skill developed over time with practice and feedback and is used by health professionals to promote lifelong learning and improve outcomes.

Initially, students were allowed to write about anything they chose. Some students did well with this, while others struggled to identify an issue or used this as a timekeeping log. Currently, topics are structured in order to further guide students and create awareness. Topics include:

1) Describe a situation which was complex, surprising, uncomfortable or uncertain using all five senses. Address your own biases and/or prejudices by reframing the encounter from a different point of view AFTER you have described it

2) What interests you about this community/practice? What seems important?

3) What do you feel you are learning about medicine and about yourself?

4) Other-student choice. For example:

a) Encounters with patients, colleagues, mentors;

b) Questions about the patients you are seeing;

c) Feelings about being in this particular community at this particular time in this particular way;

d) What is easy, difficult, puzzling, enjoyable, confusing, profound, boring, or rewarding about your experiences?

Students are required to write once per week to an assigned UNM SOM faculty mentor. At the end of the practicum, students choose one piece of their writing to read aloud in a forum that includes their classmates, faculty, other interested personnel at the UNM HSC and community.
The community service project is a group project. Each group of students addresses an important health issue identified by the local community health council (Engaging Communities, 2010). As an example, in one community, the students researched the prevalence of teen pregnancy and gathered opinions through surveys of local community members. Students present their findings to local key decision makers during the final week and submit a written summary report. Upon return to the University, students give oral and poster presentations to the upcoming practicum students, faculty and invited community members.

\section{Methods}

The Summer Practicum is evaluated by students completing a course evaluation and a service learning course survey. The first survey is an online course evaluation administered to students at the conclusion of the summer practicum course. Students are asked to assess course organization and objectives, adequacy of time to complete assignments, course syllabus/ catalog, readings, the community project and the shadowing experience with community physicians. Students rate each of 35 items on a $1-5$ scale with $1=$ strongly disagree and $5=$ strongly agree.

Completion of surveys at UNM is voluntary and all students sign an informed consent document prior to participating in survey research. The research described in this study was approved by the IRB at UNM.

\section{Results}

All sixty students from the first three classes who have completed the summer practicum course were included in this study; 21 students in each of the first two years and 18 students in the most recent year, see Table 2. Fifty-two percent of the students were female and $53 \%$ were under-represented minorities; almost two-thirds were from rural hometowns. All 60 students completed a course evaluation and 55 of 60 (92\%) completed the service learning survey.

Students generally rated the summer practicum highly; the mean overall scores for the 35 questions on the course evaluation were $3.9,3.9$, and 4.2 for cohorts 2008, 2009, and 2010 respectively. Highest rated statements were those regarding the shadowing experience as helping to understand their future role as physician; learning about community health issues; learning through the community project; and observing and learning from a physician preceptor.

\section{Discussion}

In 2010, the UNM SOM ranked as one of the top 20 US medical schools with a social mission index based on three categories: "percentage of graduates who practice primary care, work in a health professional shortage area and are underrepresented minorities (Mullan, 2010)." The Summer Practicum through the Combined BA/MD Program is a pre-medical educational model to enhance this social mission and support medical education reform.

The Summer Practicum in our Combined BA/MD Program occurs in the student's undergraduate premedical academic career (after four semesters of undergraduate work). It is designed to provide students with an exposure to the practice of medicine in rural $\mathrm{NM}$, give them tools to evaluate health from a 
Table 2.

Description of the 60 students participating in BA/MD Summer Practicum program, 2008-2010 Update through 2012.

\begin{tabular}{lc}
\hline & $\mathrm{N}(\%)$ \\
\hline Total & $60(100 \%)$ \\
Year of Summer Practicum & \\
2008 & $21(35 \%)$ \\
2009 & $21(35 \%)$ \\
2010 & $18(30 \%)$ \\
Gender & \\
Female & $31(52 \%)$ \\
Male & $29(48 \%)$ \\
Minority status & \\
Under-represented (Hispanic, Black, Native American) & $32(53 \%)$ \\
Not under-represented (Anglo, Asian) & $28(47 \%)$ \\
Hometown & \\
Rural & $38(63 \%)$ \\
Urban & $22(37 \%)$ \\
\hline
\end{tabular}

community-based approach, and involve them in a public health-based service learning project. It is critical that we prepare students to practice in rural areas by allowing them to experience the community first hand.

Overall, the results of the evaluation by the students were very positive regarding content, design and implementation. Highlights of the program for the students are reported as the shadowing experiences, community activities and learning from fellow students.

A unique aspect of this Summer Practicum is students' participation in community service learning during their undergraduate premedical education. This service learning component addresses: 1) reciprocal knowledge transfer between institutions and communities, and 2) involving community members in identifying local health priorities (Hunt, 2011). Reciprocal knowledge transfer occurs as the students are in the community. The students benefit from shadowing local community health care providers. They also learn from the community about public health issues around which they design their local community projects. The community receives the benefit of the community project which the students design and conduct. Additionally, many of these projects continue through the years with the following year's students continuing or augmenting the project. Results are reported back to the community through student presentations to appropriate organizations including local school boards, rotary clubs, members of the New Mexico Legislature, community health councils and hospital foundation boards.

Enlisting active community members is paramount. Community members are engaged early in the educational process, during the preparatory seminar series and continue to interact with the students while they are in the community. The community members who serve as local coordinators are recruited based on their reputations and roles in the health system of the communities in which they live and work. Active coordinators and the preceptors engage the students and make this course interesting. The community residents welcome the students into their homes, show them the recreational activities available and go that extra step in working with the students. They give their personal cell numbers in case of emergency, provide snacks during tutorial, and arrange for optional outings for student learning in the communities. The students remember these efforts positively. This may help students choose subsequent medical student rotations in that community. Students, who expressed hesitation in going to remote areas, came back enthusiastic about their experience and "could see themselves living in that community and practicing there".

As academic programs develop, so do the curricula, staff and faculty. In this situation, there have been changes to the faculty instructing the seminar series which may affect the students' responses. The seminar series has also been updated and adjusted annually, in part based on student feedback. Although the core content is the same, the fine tuning may have affected results. Another limitation is that the ultimate outcome of the Summer Practicum is for graduates to practice in underserved areas of NM. This outcome measure will not be assessable until at least 2017, when the first cohort could e completing their residencies and starting their medical career.

Future research for the Summer Practicum will include qualitative assessment of the community projects and the impact of the project in the local community. Also, we will conduct longitudinal studies of the students on future career choices: location (rural versus urban), setting (e.g. group, private, academic), and focus (e.g. primary care, community-based, public health, etc.). An additional area for potential research relates to whether this early experience in community service and public health will influence these individuals to be involved to a greater extent in community engagement later in their medical careers. Outcome measures regarding this will not be available for more than a decade.

In conclusion, the UNM SOM Combined BA/MD Program was designed and implemented to address medical education reform recommendations for preparing physicians for the $21 \mathrm{st}$ century. In particular, the students entering the BA Summer Practicum curriculum experience are embedded in an authentic service learning environment that prepares them to address public health and equity based issues. The Summer Practicum curriculum also initiates them into a deliberate educational ladder that continues into medical school and towards a completion of a Public Health Certificate and professional medical identity.

\section{Acknowledgements}

The authors thank Dan Gonzales and Kim Halsten-Mora of the Preceptorship Office, Karen McGillvray BA/MD Program Manager and Margaret Dornedon BA/MD Office for their outstanding coordination of all practicum logistics and tireless dedication to the program. Special acknowledgement is given to Dr. Lily Velarde for her originating ideas.

\section{REFERENCES}

Alpern, R. J., \& Long, S. (2009). AAMC-HHMI scientific foundations for future physicians (pp. 1-43). Washington DC: American Association of Medical Colleges.

Aronson, L., Kruidering, M., Niehaus, B., \& O’Sullivan, P. (2012). 
UCSF LEaP (Learning from your Experiences as a Professional): guidelines for critical reflection. MedEdPORTAL

www.mededportal.org/publication/9073

Cashman. S., \& Seifer, S. (2008). Service-learning: An integral part of undergraduate public health." American Journal of Preventive Medicine, 35(3):273-278. doi:10.1016/j.amepre.2008.06.012

Choon-Eng-Gwee, M. (2009). Problem based learning: A strategic learning system design for the education of healthcare professionals in the 21st century. Kaohsiung Journal of Medical Science, 25, 231239. doi:10.1016/S1607-551X(09)70067-1

Combined BA/MD Program University of New Mexico (n.d.). http://hsc.unm.edu/som/combinedbamd

Cosgrove, E., Harrison G., Kalishman, S., Kersting, K., Leggott-Romero, V., Timm, C., et al. (2007). Addressing physician shortages in New Mexico through a combined BA/MD program. Academic Medicine, 82, 1152-1157. doi:10.1097/ACM.0b013e318159cf06

Engaging in Communities to Serve the People of New Mexico: County Health Report Cards: UNM Health Sciences Center Office for Community Health (n.d.). Office of the vice-president for community health.

http://hsc.unm.edu/community/documents/CountyReports2010.pdf

Erwin, P. (2008). Poverty in America: How public health practice can make a difference. American Journal of Public Health, 98, 15701572. doi:10.2105/AJPH.2007.127787

Eyler, J., Giles Jr., D. E., \& Asrin, A. (1999). Resource C: Survey and interview instruments. In Where's the learning in service learning (pp. 225-274), Jossey-Bass.

Fletcher, S. W., Hager, M., Russell, S., \& Fletcher, S. W. (2008). Continuing education in the health professions: Improving healthcare through lifelong learning. Proceedings of a Conference, Bermuda: Josiah Macy, Jr. Foundation, 28 November 2007-1 December 2008.

Gebbie, K., Rosenstock, L., Hernandez, L.M. (2003) Who will keep the public healthy? Educating public health professionals for the 21st century. Washington DC: The National Academies Press.

Health Resources and Services Administration, US Department of Health and Human Services (HRSA) (2010). Find Shortage Areas: HPSA by State and County. http://hpsafind.hrsa.gov/

Hunt, J. B., Bonham, C., \& Jones, L. (2011). Understanding the goals of service learning and community-based medical education: A systematic review. Academic Medicine, 86, 246-251. doi:10.1097/ACM.0b013e3182046481

Irby, D. M., Cooke, M., \& O’Brien, B. C. (2010). Calls for reform of medical education by the Carnegie Foundation for the advancement of teaching: 1910 and 2010. Academic Medicine, 85, 220-227. doi:10.1097/ACM.0b013e3181c88449

John-Steiner, V., \& Mahn, H. (1996). Sociocultural approaches to learning and development: A Vygotskian frame work. Educational Psychology, 31, 91-206.

Kellerman, A. (2009). Emergency medicine and public health: Stopping emergencies before the 9-1-1- call. Society for Academic Emergency Medicine.

Kitsis, E. A. (2011). Shedding a light on shadowing. Journal of the American Medical Association, 305, 1029-1030. doi: 10.1001/jama.2011.267

Levine, R. B., Kern, D. E., \& Wright, S. M. (2008). The impact of prompted narrative writing during internship on reflective practce: A qualitative study. Advances in Health Sciences Education: Theory and Practice, 13, 723-733. doi:10.1007/s10459-007-9079-x

Lucian Leape Institute at the National Patient Safety Foundation (2010). Unmet needs: Teaching physicians to provide safe patient care. Boston, MS: Report of the Lucian Leape Institute Roundtable on Reforming Medical Education.

McCally, M., Haines, A., Fein, O., Addington, W., Lawrence, R., \& Cassel, C. (1998). Poverty and ill health: Physicians can, and should, make a difference. Annals of Internal Medicine, 129, 726-733. doi:10.7326/0003-4819-129-9-199811010-00009

Miller, B. M., Moore, D. E., Stead, W. W., \& Blasar, J. R. (2010). Beyond flexner: A new model for continuous learning in the health professions. Academic Medicine, 85, 266-270. doi:10.1097/ACM.0b013e3181c859fb

Mullan, F. (2010). The social mission of medical education. Annals of Internal Medicine, 52, 804-811. doi:10.7326/0003-4819-152-12-201006150-00009

US Census Bureau (2010) New Mexico Quick Links from the US Census Bureau. http://quickfacts.census.gov/qfd/states/35000lk.html

Page-Reeves, J. (2013). The nexus of poverty, hunger, and homelessness in New Mexico. Social Justice, 38, 33-41.

Rabinowitz, H. K. (1999). Demographic, educational and economic factors related to recruitment and retention of physicians in rural Pennsylvania. Journal of Rural Health, 15, 212-218. doi:10.1111/j.1748-0361.1999.tb00742.x

Robert Wood Johnson Foundation, Commission to Build a Healthier America (2009). Education matters for health.

Robert Wood Johnson Foundation: Commission to Build a Healthier America (2008). Where we live matters for our health: Neighborhoods and health.

Shaprio, J., Kaseman, D., \& Shafer, A. (2006). Words and wards: A model of reflective writing and its uses in medical education. Journal of Medical Humanities, 27, 231-244. doi:10.1007/s10912-006-9020-y

Sheu, L. C., Zheng, P., Coelho, A. D., Lin, L. D., O'Sullivan, P. S., O’Brien, B. C., et al. (2011). Learning through service: Student perceptions on volunteering at interprofessional Hepatitis B student-run clinics. Journal of Cancer Education, 26, 228-233. doi:10.1007/s13187-010-0142-6

Steinbrook, R. (2006). Imposing personal responsibility for health. New England Journal of Medicine, 355, 8. doi:10.1056/NEJMicm050051

University of New Mexico. School of Medicine. (n.d.). Strategic Plan 2010-2015. http://hsc.unm.edu/som/administration.

Woolf, S. H., Johnson, R. E., Phillips, R. L., \& Philipsen, M. (2007). Giving everyone the health of the educated: An examination of whether social change would save more lives than medical advances. American Journal of Public Health, 97, 679-683. doi:10.2105/AJPH.2005.084848

US Census Bureau (2007). Personal income per capita in current dollars. http://www.census.gov/statab/ranks/rank29.html 